\title{
The effect of prucalopride on gastric emptying in parkinson's disease patients, a pilot randomized, open-label study
}

Kanokwan Pinyopornpanish ${ }^{1}$, Atiwat Soontornpun ${ }^{2}$, Phuripong Kijdamrongthum ${ }^{1 *}$, Waralee Teeyasoontranon ${ }^{3}$ Chaisiri Angkurawaranon $^{4}$ and Satawat Thongsawat ${ }^{1}$

${ }^{1}$ Division of Gastroenterology, Department of Internal Medicine, Faculty of Medicine, Chiang Mai University, Thailand

${ }^{2}$ Division of Neurology, Department of Internal Medicine, Faculty of Medicine, Chiang Mai University, Thailand

${ }^{3}$ Division of Nuclear Medicine, Department of Radiology, Faculty of Medicine, Chiang Mai University, Thailand

${ }^{4}$ Department of Family Medicine, Faculty of Medicine, Chiang Mai University, Thailand

\begin{abstract}
Background: Gastrointestinal symptoms are common in patients with Parkinson's disease(PD) and may precede the appearance of overt neurologic symptoms. Prucalopride was approved for treatment of chronic constipation in adult. Previous study showed prucalopride also accelerates gastric emptying in healthy subjects.

Objectives: Our study aimed to evaluate the efficacy of prucalopride on gastric emptying time and compare its effect with domperidone in patients with Parkinson's disease.

Methods: A total of 10 patients with PD were enrolled in this randomized, open-label cross-over study. The patients were given prucalopride 1-2 mg daily, depending on patient's age, or domperidone $30 \mathrm{mg}$ daily. Scintigraphic gastric emptying for solid meal were performed to evaluate gastric emptying half time (GE $\mathrm{T}^{1 / 2}$ ) and percent meal retention at $120 \mathrm{~min}$ (\%RA120). Gastrointestinal symptom score, spontaneous complete bowel movements (SCBMs) per week, neurologic outcomes, and adverse events were determined. We also performed testing of potential period and potential carry-over effect before analysis the outcomes of this study.

Results: There were 5 patients in prucalopride group and 5 patients in domperidone group. Because carry-over effect of cross-over design was found, so only the outcomes measured at the first follow up period were analyzed. Prucalopride significantly improved mean gastric emptying T1/2 and \%RA120 when compared with baseline $(p=0.020$ and 0.002 , respectively) and when compared with domperidone after adjusted for baseline $(p=0.004$ and 0.008 , respectively). Prucalopride also improved difficulty in relaxing anal sphincter and Bristol stool scale compared with baseline $(\mathrm{p}=0.023$ and 0.043 , respectively). There were no significant differences between the two treatments in other gastrointestinal symptoms scores, SCBMs, neurologic outcomes and adverse events.
\end{abstract}

Conclusion: This pilot study demonstrated good efficacy of prucalopride in accelerating gastric emptying in PD patients. Further studies with more participants are highly warranted to evaluate the efficacy of prucalopride.

\begin{abstract}
Abbreviations and symbols: $\%$ RA120 = percent meal retention at 120 minutes, $99 \mathrm{mTc}=$ Technetium-99m, BSS = Bristol stool scale, $\mathrm{EMA}=$ European Medicine Agency, ENS = enteric nervous system, GE $\mathrm{T}^{1} \frac{1}{2}$ = gastric emptying half time, IQR = Interquartile range, $\mathrm{PD}=$ Parkinson's disease, $\mathrm{SCBMs}=$ spontaneous complete bowel movements, UPDRS = Unified Parkinson's Disease Rating Scale
\end{abstract}

\section{Introduction}

Parkinson's disease (PD) is a chronic progressive neurodegenerative disease, mainly causes motor disturbance. For non-motor symptoms, gastrointestinal symptoms are frequently observed, including excess salivation, dysphagia, nausea, constipation, and defecatory dysfunction [1]. One of the most common gastrointestinal symptoms is constipation, affecting over $40 \%$ of the patients [2]. Gastrointestinal symptoms are associated with motility disturbances of the entire gastrointestinal tract. Animal models of parkinsonism demonstrated involvement of enteric nervous system and dorsal motor nucleus of vagus nerve. By this mechanism, the PD patients usually develop bowel dysfunction and this abnormality occurs at the early stage of PD [3]. Moreover, patients with PD usually have significantly delayed gastric emptying time [4] from disease itself and dopaminergic drugs that may also contribute to delay gastric emptying [5]. The prevalence of delayed gastric emptying among PD is estimated to be $70 \%$ to $100 \%$ [6]. It can cause nausea, vomiting, retching, early satiety, bloating and abdominal discomfort. Additionally, since levodopa is absorbed when it reaches the proximal duodenum, the rate of gastric emptying has been considered as a rate-limiting step for levodopa absorption [7].

Correspondence to: Phuripong Kijdamrongthum, Division of Gastroenterology, Department of Medicine, Faculty of Medicine, Chiang Mai University, 110 Intawaroros, Suthep, Muang, Chiang Mai, Thailand 50200; Tel: (66)53-936446; Email: drkeng098@hotmail.com

Key words: gastric emptying, Parkinson's disease, prucalopride

Received: July 29, 2017; Accepted: September 04, 2017; Published: September 07, 2017 
It also contributes significantly to response fluctuation in patients on antiparkinsonian drugs [8].

Domperidone, a peripheral dopamine D2-receptor antagonists, has been showed to enhance gastric emptying and also increase the bioavailability of levodopa $[9,10]$. It is commonly used for treating gastrointestinal symptoms in patients with PD. However, domperidone is not available in every country. Recently, due to its potential cardiac side effects, especially in people older than 60 years old, domperidone is now restricted to short-term use in only to relief of nausea and vomiting [11].

Prucalopride is a potent, selective and specific serotonin $5-\mathrm{HT}_{4}$ receptor agonists with enterokinetic activities. Prucalopride has almost 300-fold higher affinity for the $5-\mathrm{HT}_{4}$ receptor than the hERG channel [12]. At therapeutic concentration, prucalopride provides a large safety margin [13]. Without interaction with hERG channel, less unfavorable cardiovascular side effects is expected. From previous study on safety and tolerability, administration of prucalopride does not induce QT prolongation, ventricular arrhythmias or torsades de pointes [14].

The efficacy of prucalopride has been demonstrated to improve stool frequency and consistency among patients with chronic constipation $[15,16]$ It also accelerates gastric emptying, small bowel transit time and colonic transit time in both healthy and constipated patients [1719]. Prucalopride was approved by European Medicine Agency (EMA) in 2009 for symptomatic treatment of chronic constipation in women whom laxatives fail to provide adequate relief at a dose of $2 \mathrm{mg}$ per day. Recommended starting dose for older patients (older than 65 year-old) is $1 \mathrm{mg}$ per day. Dosage of more than $2 \mathrm{mg}$ per day does not provide additional benefit over 2-mg dose [15].

Theoretically, using prucalopride in PD patients should be beneficial in accelerating gastric emptying which result in increased levodopa absorption and decreased motor fluctuation. Prucalopride can also improve gastrointestinal and colonic motility which leads to improving gastrointestinal symptoms especially constipation. In PD patients who already take a lot of medicine, once-daily administration of prucalopride can provide better compliance over three-times daily regimen of other prokinetic medications. However, the study about the effect of prucalopride on gastric emptying time in $\mathrm{PD}$ patients is still lacking. Therefore, we conducted this study aimed to evaluate the efficacy of prucalopride in comparison with domperidone and baseline in improving gastric emptying time in PD patients. We also evaluated the effects on gastrointestinal symptoms including sialorrhea, nausea, vomiting, dysphagia, bloating, constipation, on time and motor function scores.

\section{Material and methods}

\section{Study design}

This study was initially designed as a randomized open-label crossover study.

\section{Subjects}

We performed a pilot study, including 10 subjects with Parkinson's disease, who attended neurology clinic in Chiang Mai University hospital between August 2015 and November 2015, were randomized. All patients were 18-80 year of age, had fulfilled the UK Parkinson Disease Brain Bank criteria for PD and had been on stable anti-PD medications within the past 3 months. Patients were excluded if they had diabetes mellitus, chronic renal diseases, chronic liver diseases, thyroid diseases, connective tissue disorders, history of gastric surgery, prolactinoma, been pregnant, been during lactation, egg allergy, studied drug allergy or lactose intolerance.

The study was approved by Faculty of Medicine, Chiang Mai University ethical committee and accordance with Declaration of Helsinki. Patients voluntarily decided to participate in the study. We obtained written informed consent from all subjects.

\section{Study protocol}

This was initially designed as randomized open-label crossover study. Baseline data collection included clinical data and gastric emptying. The patients who took prokinetic medications were asked to stop taking that medications for at least one week prior to baseline data collection. Patients were randomized 1:1 (by using computer-generated randomization number) to receive 2 weeks of prucalopride (standard dose $2 \mathrm{mg}$ /day or $1 \mathrm{mg} /$ day if patients were older than 65 years) [20] and domperidone $(10 \mathrm{mg}$ oral three times a day). Gastric emptying time and clinical data were collected after each treatment period. The study consisted of two intervention periods of 2 weeks separated by a washout period of 1 week as in Figure 1. Because elimination half-life of prucalopride was 24-30 hours and biological half-life of domperidone was 7.5 hours so they should be totally eliminated from the body within 5 days.

Scintigraphic gastric emptying tests were performed using meal labeled Technetium-99m (99mTc)-phytate according to Thailand Adult solid meal gastric emptying scintigraphy protocol (Appendix 1). Patient were taken nothing by mouth for at least 6 hours before the study performed, except for the study medication in the morning of the study date, taken with small amount of water $(30 \mathrm{ml})$. The results of gastric emptying half time (GE T12/2) and percent meal retention at 120 minutes (\%RA120) were collected. In this study, a radiologist who interpreted gastric emptying was blinded to study medications.

Gastrointestinal symptoms including sialorrhea, nausea, vomiting, dysphagia, bloating, sensation of incomplete evacuation, difficulty in relaxing anal sphincter were evaluated. Scores adapted from Talley bowel disease questionnaire [21] of the symptoms for each category will be determined by severity and frequency. Total score will be the sum of severity and frequency scores (minimum $=0$ and maximum $=$ 6) (Appendix 2).

Neurologic outcomes, including Unified Parkinson's Disease Rating Scale for motor functions (UPDRS part III) and on time which was expressed as a percentage of time while awake, were also evaluated by a neurologist who was blinded to study medications.

All subjects reported their adverse events during the study. Concomitant anti-PD medications were continued without

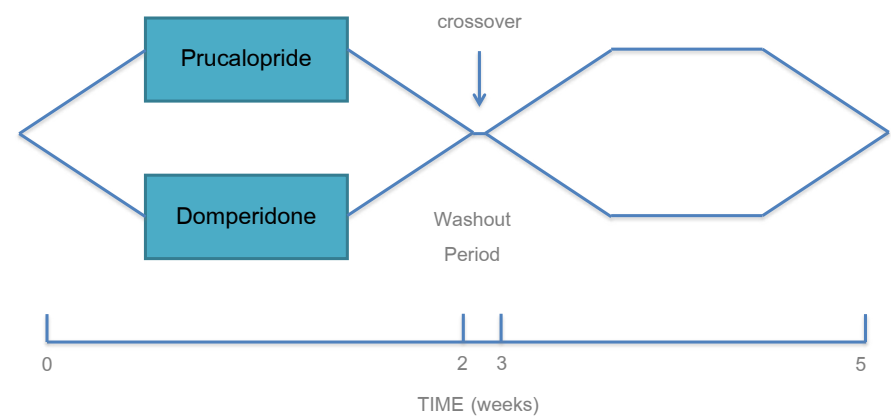

Figure 1. Study protocol. The study consisted of two intervention periods of 2 weeks separated by a washout period of 1 week 
modification during study period. Use of any medications with a potential effect on gastrointestinal motility was prohibited. The patients were allowed to use senna or enema as a rescue medication if the patient did not have a bowel movement for more than 48 hours. The use of rescue medications were recorded.

\section{Outcomes measurement}

Primary outcome was the efficacy of prucalopride in decreasing gastric emptying time in patients with Parkinson's disease and we compared this effect with domperidone. Secondary outcomes were gastrointestinal symptoms, using gastrointestinal symptoms score, frequency of spontaneous complete bowel movements (SCBMs) per week, proportion of patients with an increase of at least 1 SCBMs from baseline, Bristol stool scale (BSS), neurologic assessment, using UPDRS III and percent on time and treatment related adverse events.

\section{Statistical analysis}

We investigated potential period and carry-over effects of the crossover design. In the absence of these effects, the results from both periods will be combined. In the presence of these effects, the results will be analyzed as a randomized control trial where only the outcomes measured at the first follow up period will be analyzed. Baseline characteristics and clinical data were presented in percentages, mean $+\mathrm{SD}$ or median (IQR) as appropriate. Comparison of parameters between after treatment and baseline, paired $t$-test was used for analysis of GE T12 and \%RA120. Comparison between treatment groups, t-test was used for analysis of gastric emptying half time, percent meal retention, on-time and UPDRS score.

Gastrointestinal symptoms scores, frequency of SCBMs per week and proportion of patients with an increase of at least 1 SCBMs from baseline, BSS, adverse event rates and adherence rates were analyzed by McNemar's or Chi-square test as appropriate.

Stata statistical software version 12.0 (Stata Statistical Software: Release 12.0, Stata Corporation, College Station, TX, 2011) were used for all statistical analysis. p-value of less than 0.05 was considered statistically significant.

\section{Results}

\section{Baseline characteristics}

The clinical characteristics of the patients were shown in Table 1. Fifty percent of patients were female. The mean duration of PD was 11.2 \pm 6.48 years. The median modified Hoehn and Yahr stage was 2.75 (IQR 2 to 4). All patients reported constipation. Median SCBMs per week was 1 (IQR 0 to3). There were 2 and 3 patients in prucalopride group, who received $1 \mathrm{mg}$ /day and $2 \mathrm{mg} /$ day of prucalopride, respectively.

After we investigated the potential period and carry-over effects, we found carry-over effect in this study as shown in Table 2 and Figure 2. Therefore, the subsequent findings are results which were analyzed as a randomized control trial where only the outcomes measured at the first follow up period will be used.

At baseline, no statistical significant differences between prucalopride and domperidone group were noted, however, mean gastric emptying half time was lower in prucalopride group (63.9 \pm 32.73 ) compared with domperidone group $(88.0 \pm 97.98)$, but this difference did not reach statistical significant $(\mathrm{p}=0.616)$. There was one patient in domperidone group who had previously prescribed domperidone ( $20 \mathrm{mg} /$ day). This patient discontinued domperidone for two weeks before baseline evaluation.
Table1. Baseline characteristics

\begin{tabular}{|c|c|c|c|c|}
\hline & $\begin{array}{l}\text { All patients } \\
\qquad(\mathrm{n}=10)\end{array}$ & $\begin{array}{c}\text { Prucalopride } \\
\text { group } \\
(\mathbf{n}=5)\end{array}$ & $\begin{array}{c}\text { Domperidone } \\
\text { group } \\
(\mathbf{n}=\mathbf{5})\end{array}$ & P-value \\
\hline Age (yr) & $63.1 \pm 7.72$ & $64.4 \pm 6.18$ & $61.8 \pm 4.28$ & 0.624 \\
\hline Sex (Female) & $5(50 \%)$ & $2(40 \%)$ & $3(60 \%)$ & 0.500 \\
\hline $\begin{array}{l}\text { Disease duration } \\
(\mathrm{yr})\end{array}$ & $11.2 \pm 6.48$ & $12.4 \pm 8.01$ & $10 \pm 5.47$ & 0.595 \\
\hline MHY scale & $2.75(2,4)$ & $3(2,3)$ & $2.5(2.5,4)$ & 0.749 \\
\hline \multicolumn{5}{|c|}{ Gastric emptying study } \\
\hline$-\mathrm{T} 1 / 2(\min )$ & $75.9 \pm 70.03$ & $63.9 \pm 32.73$ & $88.0 \pm 97.98$ & 0.616 \\
\hline - \%RA120 (\%) & $25.95 \pm 21.95$ & $24.92 \pm 15.33$ & $26.98 \pm 29.09$ & 0.892 \\
\hline \multicolumn{5}{|c|}{ GI symptoms scores } \\
\hline - Sialorrhea & $3(0,4)$ & $4(0,4)$ & $3(0,3)$ & 0.443 \\
\hline - Nausea & $0(0,0)$ & $0(0,0)$ & $0(0,0)$ & 1.000 \\
\hline - Vomiting & $0(0,0)$ & $0(0,0)$ & $0(0,0)$ & 0.882 \\
\hline - Dysphagia & $0(0,0)$ & $0(0,0)$ & $0(0,0)$ & 1.000 \\
\hline - Bloating & $3(2,4)$ & $2(2,3)$ & $4(3,4)$ & 0.455 \\
\hline $\begin{array}{l}\text { - Incomplete } \\
\text { evacuation }\end{array}$ & $4.5(4,5)$ & $4(4,5)$ & $5(4,5)$ & 0.829 \\
\hline $\begin{array}{l}\text { - Difficulty in } \\
\text { relaxing anal } \\
\text { sphincter }\end{array}$ & $5(5,6)$ & $6(5,6)$ & $5(5,5)$ & 0.371 \\
\hline SCBMs / week & $1(0,3)$ & $2(0,3)$ & $0(0,3)$ & 0.572 \\
\hline BSS & $1.5(1,2)$ & $1(1,1)$ & $2(2,3)$ & 0.054 \\
\hline \multicolumn{5}{|c|}{ Neurological status } \\
\hline On time $(\%)$ & $\begin{array}{l}84.14 \pm 9.40 \\
(\mathrm{n}=7)\end{array}$ & $\begin{array}{l}77.33 \pm 5.13 \\
(\mathrm{n}=3)\end{array}$ & $\begin{array}{l}89.25 \pm 8.84 \\
(n=4)\end{array}$ & 0.094 \\
\hline UPDRS & $9.7 \pm 5.61$ & $11.2 \pm 6.94$ & $8.2 \pm 4.14$ & 0.430 \\
\hline
\end{tabular}

MHY, Modified Hoehn and Yahr scale; T1/2, gastric emptying half time; \%RA120, percen meal retention at $120 \mathrm{~min}$; SCBMs, Spontaneous complete bowel movements; BSS, Bristol stool scale; UPDRS, Unified Parkinson's Disease Rating scale

Table 2. Gastric emptying half time outcomes from a two-treatment, two period crossover trial

\begin{tabular}{|l|l|l|l|}
\hline \multirow{2}{*}{ Treatment sequence } & \multicolumn{2}{|c|}{ Treatment period } & \multirow{2}{*}{$\begin{array}{c}\text { Within-individual } \\
\text { difference }\end{array}$} \\
\cline { 2 - 3 } & \multicolumn{2}{|c|}{$\mathbf{2}$} & \\
\hline prucalopride then domperidone & $41.5 \pm 21.14$ & $36.48 \pm 11.60$ & $5.02 \pm 10.59$ \\
\hline Mean (SD) & 5 & 5 & 5 \\
\hline Sample size & $88.06 \pm 82.45$ & $63.94 \pm 23.11$ & $-24.12 \pm 34.47$ \\
\hline domperidone then prucalopride & 5 & 5 \\
\hline Mean (SD) & 5 & & \\
\hline Sample size & & & $-9.55 \pm 28.52$ \\
\hline Treatment effect & & & 10 \\
\hline Mean (SD) & & 0.317 \\
\hline Sample size & & \\
\hline $\begin{array}{l}\text { T-test for paired } \\
\text { samples }\end{array}$ & & & $10.95,10.85)$ \\
\hline
\end{tabular}

\section{Gastric emptying scintigraphy}

Comparing to baseline, GE T $1 \frac{1}{2}$ and $\%$ RA120 significantly decreased during treatment with prucalopride ( $\mathrm{p}=0.020$ and 0.002 , respectively) (Figure $3 \mathrm{~A}$ and $3 \mathrm{~B}$ ). These parameters were not significantly decrease during treatment with domperidone $(\mathrm{p}=0.994$ and 0.955 , respectively) (Figure 3C and 3D). After adjusted for baseline, mean $\mathrm{GE} \mathrm{T}^{1} \frac{1}{2}$ and \%RA120 statistically significant decreased during prucalopride treatment compared with domperidone treatment $(\mathrm{p}=0.004$ and 0.008 , respectively) (Table 3).

\section{Gastrointestinal symptoms}

Median baseline symptom score for difficulty in relaxing anal sphincter was 6 (IQR 5 to 6) and was significantly decreased to 4 (IQR 3 to 4 ) during prucalopride treatment, $\mathrm{p}=0.023$ (Table 4). Improvement 
Table 3. Gastric emptying time

\begin{tabular}{|c|c|c|c|c|c|c|}
\hline Gastric emptying & Prucalopride $(n=5)$ & $\begin{array}{c}\text { Domperidone } \\
(n=5)\end{array}$ & $\begin{array}{l}\text { Differences } \\
(95 \% \text { CI) }\end{array}$ & P value & $\begin{array}{l}\text { Adjusted mean } \\
\text { difference }\end{array}$ & Adjusted P-value \\
\hline T $1 / 2(\min )$ & $41.5 \pm 21.14$ & $88.06 \pm 82.45$ & $\begin{array}{c}-46.56 \\
(-134.34,41.22)\end{array}$ & 0.256 & $\begin{array}{c}-46.56 \\
(-134.34,41.22)\end{array}$ & 0.004 \\
\hline \% RA 120 (\%) & $13.46 \pm 12.58$ & $26.72 \pm 22.46$ & $\begin{array}{c}-13.26 \\
(-39.81,13.29)\end{array}$ & 0.282 & $\begin{array}{c}-13.26 \\
(-39.81,13.29)\end{array}$ & 0.008 \\
\hline
\end{tabular}

$\mathrm{T} 1 / 2$, gastric emptying half time; \%RA120, percent meal retention at $120 \mathrm{~min}$

Table 4. Gastrointestinal symptom score

\begin{tabular}{|c|c|c|c|}
\hline Symptoms & $\begin{array}{c}\text { Prucalopride } \\
(\mathbf{n}=\mathbf{5})\end{array}$ & $\begin{array}{c}\text { Domperidone } \\
(\mathbf{n}=\mathbf{5})\end{array}$ & P-value \\
\hline - Sialorrhea & $0(0,3)$ & $2(0,3)$ & 0.823 \\
\hline - Nausea & $0(0,0)$ & $0(0,0)$ & 0.317 \\
\hline - Vomiting & $0(0,0)$ & $0(0,0)$ & 0.317 \\
\hline - Dysphagia & $0(0,0)$ & $0(0,0)$ & 0.317 \\
\hline - Bloating & $2(2,3)$ & $3(2,4)$ & 0.076 \\
\hline $\begin{array}{c}\text { - Incomplete } \\
\text { evacuation }\end{array}$ & $4(3,4)$ & $5(4,5)$ & 0.747 \\
\hline $\begin{array}{c}\text { - Difficulty in } \\
\text { relaxing anal } \\
\text { sphincter }\end{array}$ & $3(3,4) *$ & $5(4,5)$ & 0.268 \\
\hline $\begin{array}{c}\text { SCBMs } / \text { week } \\
\text { Changes of No of } \\
\text { SCBMs/wk }\end{array}$ & $3(2,4)$ & $3(2,3)$ & 0.513 \\
\hline $\begin{array}{c}\text { Increase of } \geq 1 \\
\text { SCBMs/wk (No) } \%\end{array}$ & $2(40 \%)$ & $0(0,2)$ & 0.654 \\
\hline BSS & $3(2,3) \dagger$ & $2(40 \%)$ & 1.000 \\
\hline BSS Changes & $1(1,2)$ & $3(2,4)$ & 0.519 \\
\hline
\end{tabular}

SCBMs, Spontaneous complete bowel movements; BSS, Bristol stool scale

* P-value 0.023 compared to baseline

† P-value 0.043 compared to baseline

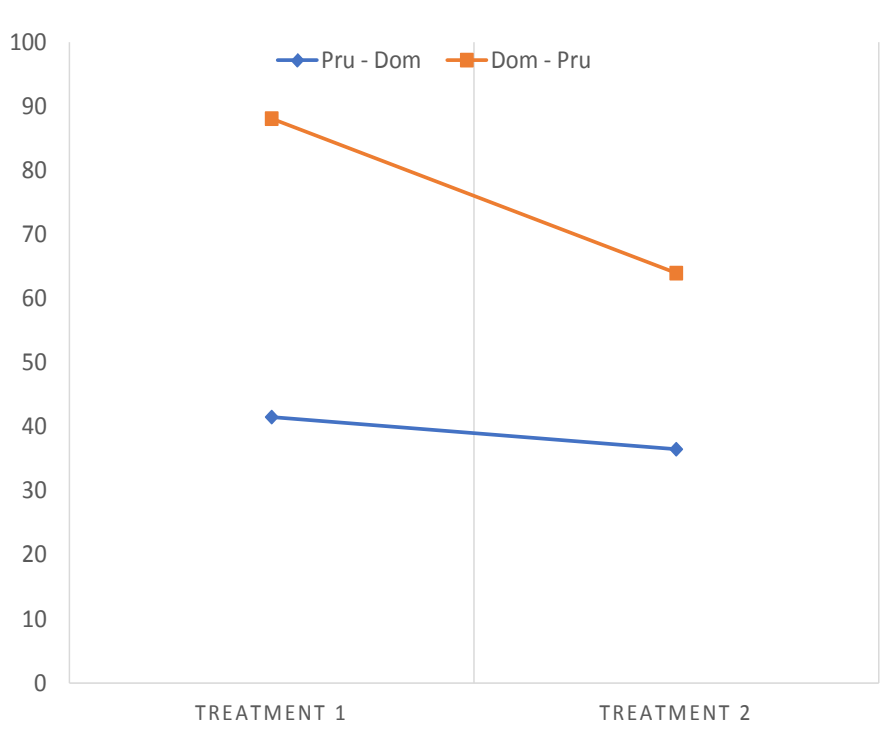

Figure 2. Gastric emptying half time of two intervention group

in median BSS was also observed in prucalopride group compared with baseline (from 1.5 (IQR 1 to 2 ) at baseline to 3 (IQR 2 to 3 ), p = 0.043). Other symptom scores and SCBMs per week were not different comparing with baseline and another treatment.

\section{Neurological symptoms}

There were no differences in percent on time and UPDRS motor function comparing with baseline and another treatment (Table 5).

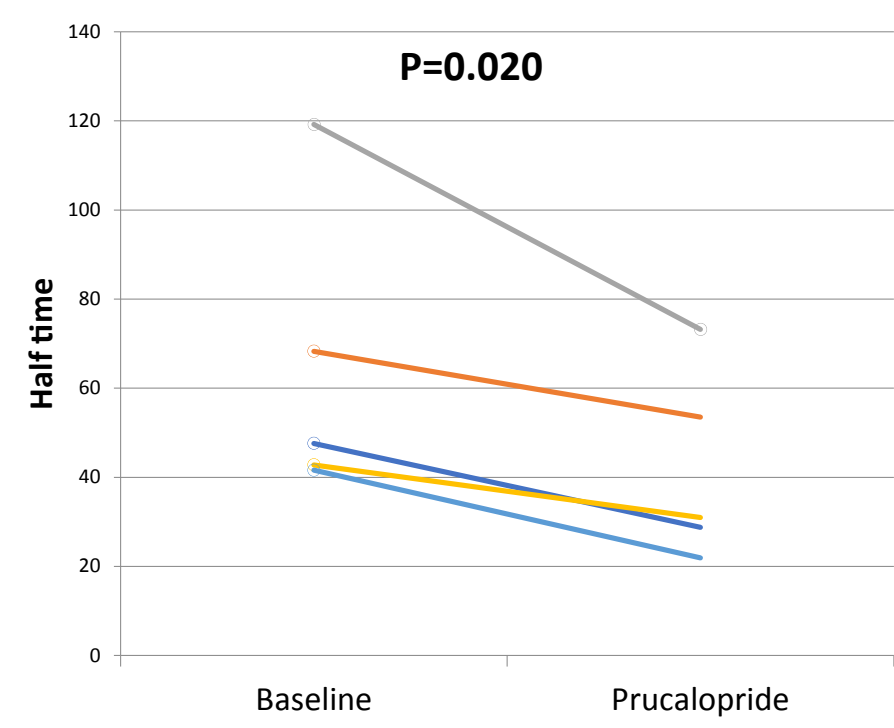

Figure 3A. Gastric emptying time compared to baseline in prucalopride and domperidone group (A) GE T1/2 in Prucalopride group

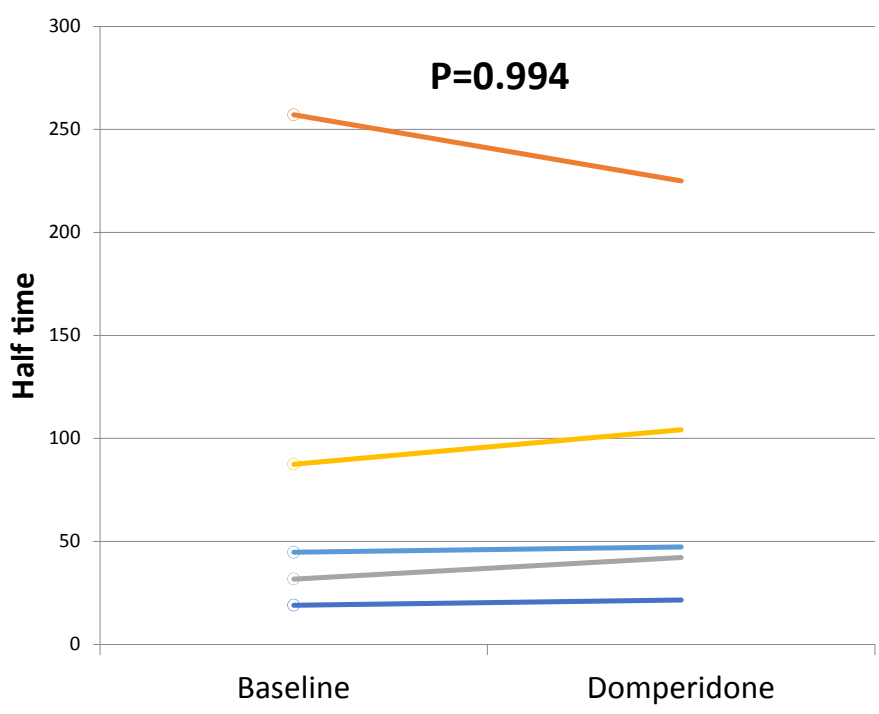

Figure 3B. Gastric emptying time compared to baseline in prucalopride and domperidone group (B) \%RA120 in Prucalopride group

Table 5. Neurologic outcomes

\begin{tabular}{|c|c|c|c|c|c|}
\hline Outcomes & $\begin{array}{c}\text { Prucalopride } \\
(\mathbf{n = 5})\end{array}$ & $\begin{array}{c}\text { Domperidone } \\
(\mathbf{n}=\mathbf{5})\end{array}$ & $\begin{array}{c}\text { Difference } \\
\mathbf{( 9 5 \%} \mathbf{C I})\end{array}$ & P-value & $\begin{array}{c}\text { Adjusted } \\
\text { P-value }\end{array}$ \\
\hline $\begin{array}{c}\text { Percent On } \\
\text { time } \\
(\mathrm{n}=7)\end{array}$ & $\begin{array}{c}80.33 \pm 5.85 \\
(\mathrm{n}=3)\end{array}$ & $\begin{array}{c}91.25 \pm 10.11 \\
(\mathrm{n}=4)\end{array}$ & $\begin{array}{c}-10.91 \\
(-27.92,6.10)\end{array}$ & 0.160 & 0.813 \\
\hline UPDRS III & $9.4 \pm 8.53$ & $7 \pm 4.24$ & $\begin{array}{c}2.4 \\
(-7.42,12.22)\end{array}$ & 0.588 & 0.847 \\
\hline
\end{tabular}

UPDRS, Unified Parkinson's Disease Rating scale 


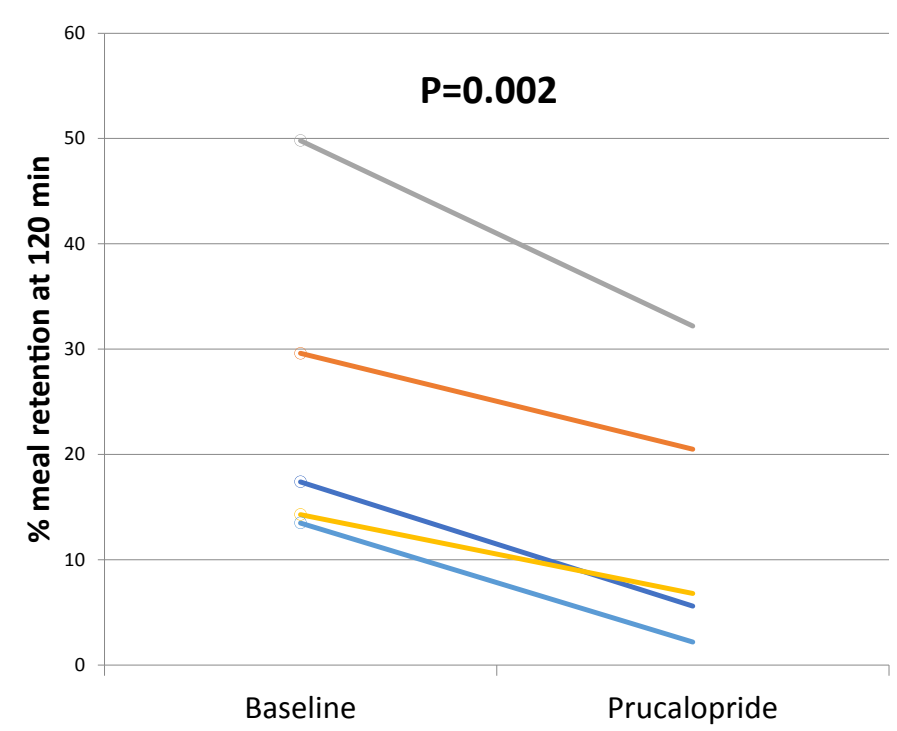

Figure 3C. Gastric emptying time compared to baseline in prucalopride and domperidone group (C) GE T1/2 in Domperidone group

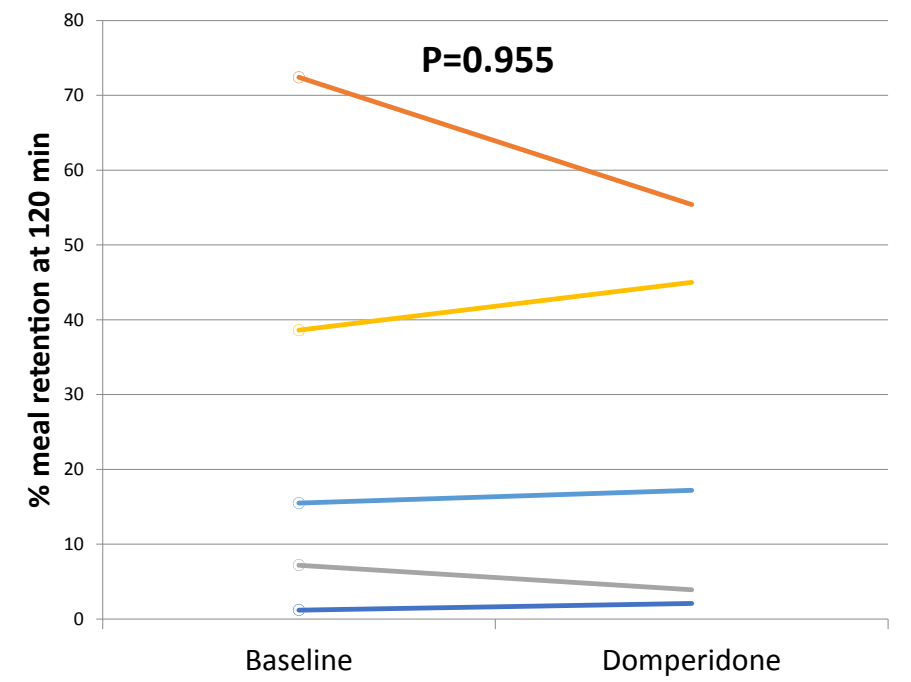

Figure 3D. Gastric emptying time compared to baseline in prucalopride and domperidone (D) \%RA120 in Domperidone group

\section{Adverse events and medication adherence}

The adverse events experienced during the study were reported in table 6. Five patients reported side effects during treatment with prucalopride and two reported side effects during treatment with domperidone. Three patients who received prucalopride had abnormal bowel sound and one had abdominal pain. We did not find these side effects in domperidone group. These adverse events were mild and required no medical intervention. No serious adverse event was reported and there was no discontinuation due to adverse events. All patients in this study reported more than $90 \%$ adherence to study medications.

\section{Discussion}

This study demonstrates decreased GE T $1 / 2$ and \%RA120 after 2 weeks of standard dose (1-2 mg) prucalopride in patients with PD. In addition, gastric emptying time was significantly lower in prucalopride group than domperidone group. From previous studies on healthy
Table 6. Adverse events

\begin{tabular}{|c|c|c|}
\hline & $\begin{array}{c}\text { Prucalopride (n=5) } \\
\mathbf{n}(\mathbf{\%})\end{array}$ & $\begin{array}{c}\text { Domperidone (n=5) } \\
\mathbf{n}(\mathbf{\%})\end{array}$ \\
\hline Abnormal bowel sound & $3(60 \%)$ & 0 \\
\hline Tiredness & $1(20 \%)$ & $1(20 \%)$ \\
\hline Abdominal pain & $1(20 \%)$ & 0 \\
\hline Loss of appetite & 0 & $1(20 \%)$ \\
\hline Headache & 0 & 0 \\
\hline Galactorrhea & 0 & 0 \\
\hline
\end{tabular}

subjects, prucalopride showed significant improvement of gastric emptying time [18]. Despite lower dosage of prucalopride was used in our study (1-2 mg/day and $4 \mathrm{mg} /$ day in the previous study) and abnormalities of ENS in PD patients, the results of this study showed that prucalopride also provided good efficacy in reducing gastric emptying time in PD patients.

The normal recommended washout period was 5 times of elimination half-life. Elimination half-life of prucalopride was 2430 hours so the washout period of 7 days should be long enough to eliminate prucalopride. However, this study showed significant carryover effect in prucalopride then domperidone group, which indicated inadequate washout time for prucalopride. This might be related to the high affinity binding of prucalopride to $5-\mathrm{HT}_{4}$ receptors. Therefore, longer washout period should be considered for the future study.

Previous study by Soykan et al. [10] showed that domperidone (20 $\mathrm{mg}$, four times daily) significantly improved gastric emptying in PD patients and also improved upper gastrointestinal symptoms, including nausea, vomiting, anorexia, bloating, heartburn and regurgitation [10]. In contrast, domperidone failed to showed this effect in our study. In the previous study, domperidone dosage was higher ( $80 \mathrm{mg}$ per day) and longer (more than 4 months) than our study. For these reasons, the difference between two trial results might be due to difference in drug dose and duration of treatment. Our results suggested that 30 $\mathrm{mg}$ of domperidone per day might not be enough to improve gastric emptying in PD patients. Reasons for requiring higher dosage likely due to the degeneration of autonomic nerves and the suppression of cholinergic transmission by antiparkinsonian drugs.

In our study, the patients also reported improvement in difficulty in relaxing anal sphincter and BSS during prucalopride treatment. Improvement of BSS indicated improvement in stool consistency, however, prucalopride failed to demonstrate increase in SCBMs which was a significant endpoint of improvement of constipation. This result differed from other previous studies which showed improvement in both stool consistency and frequency in individuals taking prucalopride $[15,16]$. Because there were limited participants, this effect may occur by chance.

Although a standard dose of prucalopride significantly shortened gastric emptying half-time, this study did not show any beneficial effect of prucalopride on percent on time and UPDRS motor function score. Asai et al. [22] reported increased gastric motility and reduced gastric retention of anti-PD drugs during treatment with mosapride and prolonged on time and decreased UPDRS score were also found in this study. Our study could not show these beneficial effects might be from higher percent on time at baseline, which was $77 \%$ in our study and $69 \%$ in Asai's study, and lower UPDRS score during on period at baseline (11 in our study and 44 in Asai's study). Better motor control is attributed to medical care including better medical treatment.

Our study had some limitations. First, there was carry-over effect so the analysis had to be changed. Second, the relatively small numbers 
of participants limited the study power. Finally, there were missing ontime data in 3 participants, which further limited the data for analysis.

\section{Conclusions}

This study demonstrated good efficacy of prucalopride in accelerating gastric emptying in PD patients. Further study with more participants appears highly warranted to evaluate the efficacy of prucalopride in advanced PD patients with motor fluctuation.

\section{Authors' contribution}

$\mathrm{KP}, \mathrm{PK}, \mathrm{ST}$ were responsible for the conception of the study and design. KP, AS, WT were responsible for acquisition of data. KP and $\mathrm{CA}$ analyzed the data. KP wrote the first draft of the manuscript. All authors contributed to interpretation of the data, revised the manuscript and approved the final manuscript.

\section{Acknowledgement}

We are grateful to all staffs who helped collect the data and to all participants who participated in our study.

\section{Funding information}

Research fund from Faculty of Medicine, Chiang Mai University

\section{Competing interests}

The Authors declare that there is no conflict of interest.

\section{References}

1. Pfeiffer RF (1998) Gastrointestinal dysfunction in Parkinson's disease. Clin Neurosci 5: 136-146. [Crossref]

2. Khoo TK, Yarnall AJ, Duncan GW, Coleman S, O’Brien JT, et al. (2013) The spectrum of nonmotor symptoms in early Parkinson disease. Neurology 80(3): 276-281. [Crossref]

3. Pfeiffer RF (2012) Gastrointestinal Dysfunction in Parkinson's Disease. In: Ronald F. Pfeiffer ME, editor. Parkinson's Disease. Second ed: CRC Press 309-326.

4. Krygowska-Wajs A, Cheshire WP Jr, Wszolek ZK, Hubalewska-Dydejczyk A, Jasinska-Myga B, et al. (2009) Evaluation of gastric emptying in familial and sporadic Parkinson disease. Parkinsonism Relat Disord 15(9): 692-696. [Crossref]

5. Robertson DR, Renwick AG, Macklin B, Jones S, Waller DG, et al. (1992) The influence of levodopa on gastric emptying in healthy elderly volunteers. Eur J Clin Pharmacol 42: 409-412. [Crossref]
6. Heetun ZS, Quigley EM (2012) Gastroparesis and Parkinson's disease: a systematic review. Parkinsonism Relat Disord 18: 433-440. [Crossref]

7. Nyholm D1, Lennernäs H (2008) Irregular gastrointestinal drug absorption in Parkinson's disease. Expert Opin Drug Metab Toxicol 4: 193-203. [Crossref]

8. Marrinan S1, Emmanuel AV, Burn DJ (2014) Delayed gastric emptying in Parkinson's disease. Mov Disord 29: 23-32. [Crossref]

9. Nishikawa N, Nagai M, Tsujii T, Iwaki H, Yabe H, et al. (2012) Coadministration of domperidone increases plasma levodopa concentration in patients with Parkinson disease. Clin Neuropharmacol 35(4): 182-184. [Crossref]

10. Soykan I, Sarosiek I, Shifflett J, Wooten GF, McCallum RW (1997) Effect of chronic oral domperidone therapy on gastrointestinal symptoms and gastric emptying in patients with Parkinson's disease. Mov Disord 12: 952-957. [Crossref]

11. Agency MaHpR. Domperidone: risks of cardiac side effects. Drug Safety Update Volume 72014. p A1.

12. Wong BS, Manabe N, Camilleri M (2010) Role of prucalopride, a serotonin (5-HT(4)) receptor agonist, for the treatment of chronic constipation. Clin Exp Gastroenterol 3: 49-56. [Crossref]

13. Chapman H, Pasternack M (2007) The action of the novel gastrointestinal prokinetic prucalopride on the HERG K+ channel and the common T897 polymorph. Eur J Pharmacol 554(2-3): 98-105. [Crossref]

14. Camilleri M, Beyens G, Kerstens R, Robinson P, Vandeplassche L (2009) Safety assessment of prucalopride in elderly patients with constipation: a double-blind, placebo-controlled study. Neurogastroenterol Motil 21(12): 1256-e117. [Crossref]

15. Camilleri M, Kerstens R, Rykx A, Vandeplassche L (2008) A placebo-controlled trial of prucalopride for severe chronic constipation. $N$ Engl J Med 358: 2344-2354. [Crossref]

16. Tack J, Stanghellini V, Dubois D, Joseph A, Vandeplassche L, et al. (2014) Effect of prucalopride on symptoms of chronic constipation. Neurogastroenterol Motil 26(1): 21-27. [Crossref]

17. Bouras EP, Camilleri M, Burton DD, Thomforde G, McKinzie S, et al. (2001) Prucalopride accelerates gastrointestinal and colonic transit in patients with constipation without a rectal evacuation disorder. Gastroenterology 120(2): 354-360. [Crossref]

18. Kessing BF, Smout AJ, Bennink RJ, Kraaijpoel N, Oors JM, et al. (2014) Prucalopride decreases esophageal acid exposure and accelerates gastric emptying in healthy subjects. Neurogastroenterol Motil 26(8): 1079-86. [Crossref]

19. Bouras EP, Camilleri M, Burton DD, McKinzie S (1999) Selective stimulation of colonic transit by the benzofuran 5HT4 agonist, prucalopride, in healthy humans. Gut 44: 682686. [Crossref]

20. Resolor Product Information.

21. Talley NJ, Phillips SF, Melton J 3rd, Wiltgen C, Zinsmeister AR (1989) A patien questionnaire to identify bowel disease. Ann Intern Med 111: 671-674. [Crossref]

22. Asai H, Udaka F, Hirano M, Minami T, Oda M, et al. (2005) Increased gastric motility during 5-HT4 agonist therapy reduces response fluctuations in Parkinson's disease. Parkinsonism Relat Disord 11(8): 499-502. [Crossref]

Copyright: (C2017 Pinyopornpanish K. This is an open-access article distributed under the terms of the Creative Commons Attribution License, which permits unrestricted use, distribution, and reproduction in any medium, provided the original author and source are credited. 